\title{
Proposed Child Protection Information System seems to run counter to best evidence
}

\author{
Jenny Woodman researcher, Ruth Gilbert professor
}

UCL-Institute of Child Health, London WC1N 1EH, UK

We are worried that the Child Protection Information System (CPIS) described by Hawkes runs counter to best available evidence.

CPIS focuses on children presenting to emergency departments (A\&E) who are subject to a child protection plan (CPP) or are in out-of-home care. However, maltreatment rarely causes injury or medical problems ${ }^{2}$ - less than $1 \%$ of child A\&E attendances for injury are maltreatment related. ${ }^{3}$ Maltreatment is usually identified through unrelated medical presentations or through parents. $^{4}$

As proposed, CPIS will miss most maltreated children. Although 4-10\% of children experience maltreatment annually, few are placed on a CPP $(0.5 \%$ of all children $)$ or in out-of-home care $(0.2 \%)$. Because our systematic review found no evidence that maltreated children have substantially more A\&E attendances than non-maltreated ones, ${ }^{5}$ it is unclear how professionals should interpret CPIS data on recurrent attendances.

Knowing that a child is not currently the subject of a plan or in out-of-home care adds little useful information about risk status but could falsely reassure clinicians and lead to missed cases.

Given the lack of evidence for the focus of CPIS and its potential for harm, rigorous evaluation is essential. Analysing anonymous and linked routinely captured data from health and social care would help to predict how and with whom information on contacts with CSC could best be shared. Until such evidence is available, children (or parents) attending $\mathrm{A} \& \mathrm{E}$ who prompt concerns should be followed up in the community. GPs are well placed to respond to the most prevalent forms of maltreatment — chronic neglect and emotional abuse-and parental risk factors, such as drug or alcohol misuse. A focus on family doctors would be a good start for investigating where information on CSC services might lead to the most effective responses for vulnerable children. ${ }^{4}$

Competing interests: None declared.

1. Hawkes N. Proposed system to detect child abuse could deter parents from seeking treatment, pressure group says. BMJ 2012;345:e8705. (28 December.)

Ruiz-Casares M, Trocme N, Fallon B. Supervisory neglect and risk of harm. Evidence from the Canadian child welfare system. Child Abuse Negl 2012;36:471-80.

3 Woodman J, Pitt M, Wentz R, Taylor B, Hodes D, Gilbert RE. Performance of screening tests for child physical abuse in accident and emergency departments. Health Technol Assess 2008;12(33):iii, xi-xiii, 1-95.

4 Woodman J, Allister J, Rafi I, de Lusignan S, Belsey J, Petersen I, et al. Simple approaches to improve recording of concerns about child maltreatment in primary care records: developing a quality improvement intervention. Br J Gen Pract 2012;62:e478-86(9).

5 Woodman J, Lecky F, Hodes D, Pitt M, Taylor B, Gilbert R. Screening injured children for physical abuse or neglect in emergency departments: a systematic review. Child Care Health Dev 2010;36:153-64.

Cite this as: BMJ 2013;346:5504

๑ BMJ Publishing Group Ltd 2013 